\title{
Pedagogia do acolhimento: reflexões sobre a poética do espaço em Bachelard
}

\author{
William Gustavo Machado ${ }^{1}$
}

Gabriel Kafure da Rocha ${ }^{2}$

\section{Introdução}

O presente trabalho está desenvolvido em torno da temática do acolhimento na educação, mais especificamente, com base nos estudos da imaginação do filósofo Gaston Bachelard (1884-1962), esta é uma reflexão de cunho filosófico com a intenção de abrir-se ao novo, às possibilidades que possam derivar desse processo de imaginação da função de habitar. Sendo assim, como de costume na filosofia, o trabalho desenvolvido é uma revisão bibliográfica sustentada por exemplos práticos da educação: reflexões a partir de um filósofo, costurando com outros da mesma ou de outras áreas para se re-pensar princípios.

Por meio de tal pesquisa, compreende-se que o filosofar acerca de uma pedagogia do acolhimento, no que se refere ao seu papel de receber o ser-criança no mundo, seja fundamental e, talvez, seja um exercício inacabável, visto que as culturas se movem, no tempo e no espaço, e os seres que vem ao mundo solicitam sempre por demandas singulares. Em vista desse olhar, recorre-se à obra A Poética do Espaço (originalmente publicada em 1957) de Gaston Bachelard para embasar o exercício filosófico que aqui pisa em um terreno tão inseguro e fértil como é o do imaginário, da imaginação e dos sonhos.

\section{A psicossocialidade dos espaços não-formais da educação}

Ao partir da ideia do acolhimento para uma abertura enquanto possibilidade pedagógica, Bachelard se mostra um filósofo que pode ser compreendido e classificado como diurno e noturno, por sua obra ter características poéticas e epistemológicas. Partiremos então da sua

\footnotetext{
${ }^{1}$ Graduando em Filosofia (Bacharelado) pelo Centro Universitário UNINTER, Caxias do Sul (RS), wgmachado1991@gmail.com 2 Professor de Filosofia e Docente permanente do PPG PROFEPT do IFSertãoPE e Professor Permanente do Mestrado Acadêmico em Filosofia Cmaf UECE, Petrolina PE, e-mail gabriel.rocha@ifsertao-pe.edu.br
}

Periódico Horizontes - USF - Itatiba, SP - Brasil - e021048 
vertente poética, na qual o livro $A$ poética do espaço será estudado no viés da imaginação da casa e da chamada função ontológica do habitar.

Bachelard sugere que as instâncias diurnas e noturnas devem ser compreendidas como um desdobramento dos conceitos animus e a ânima que partiram da psicologia analítica junguiana, delimitando e denominando essas duas grandes forças e manifestações como formas arquetípicas profundas. "Os arquétipos não são derivados da cultura; pelo contrário, as formas culturais (na teoria de Jung) é que derivam de arquétipos" (STEIN, 2000, p.116). O animus como polo masculino é o pai simbólico, como entende a psicanálise. Ele vai gerar os canais por onde operam a ciência ou a subida do eixo verticalizador. Bachelard entendia que esse lado/polo psíquico opera diferente da ânima. A esfera masculina gera a ciência partindo de um não, buscando eliminar as imagens primeiras. Quando uma subjetividade tem contato com a imagem, a postura científica vai negar e eliminar impressão primeira para não ter que girar em círculos para toda vontade de descoberta.

Enquanto para o lado feminino da ânima tudo é considerado pelo sim e acolhimento, o que é interessante dessa abertura é que justamente ao não negar nada, surge a abertura do ser que devém do Imaginário. Por essa via, o antropólogo Gilbert Durand, discípulo de Bachelard, em sua obra As estruturas antropológicas do imaginário, relata todo o preconceito que o Ocidente logocentrista teve contra o Imaginário e o rigor de seus estudos, sendo então classificado preconceituosamente enquanto fonte do erro epistemológico.

É a partir do surrealismo, psicanálise e outros movimentos das ciências humanas, que vai surgir esse re-acolhimento, essa realocação do Imaginário como área de estudos das ciências humanas pelos quais é possível encontrar modalidades profundas do ser, como afirmou Mircea Eliade (1991), outro pensador do Círculo de Eranos, assim como Jung e Durand.

Por meio então da poesia, o lado noturno bachelardiano, formulamos a pergunta de quais são as imagens/ânima da educação? Na educação, tanto formal quanto informal, se existe um espaço para reflexões desse eixo feminino e poético, é possível o acolhimento sem uma classificação, julgamento e intenção de subida? Com essa provocação, será possível fazer além do que está dado? Por essa via, adentramos na fenomenologia bachelardiana pensando nessa casa imaginária, nesse espaço ânima, e relacionamos a poética do espaço com a Educação. A pedagogia pode ser entendida aqui com Gilbert Durand como um ambiente psicossocial. 
[...] é preciso explicar bem o que entendemos por pressão histórica: trata-se apenas da pressão ocorrencial das ideologias dum instante de uma civilização, e para significar essa pressão preferimos chamá-la 'pedagogia' mais do que história, porque este último termo presta-se a confusão, na mentalidade dos dois últimos séculos, precisamente com um mito messiânico e progressista (DURAND, 2002, p.384).

Tais nuances psicossociais que partiram do que a fenomenologia bachelardiana apresenta abrem ao pensamento pedagógico como novas possibilidades. A filosofia que se constrói aqui se refere ao que é mais subjetivo no ser humano, esse terreno imaginante proporciona a criação, gênese de relações de alteridade. Para acolher, enquanto uma pedagogia, um sistema educacional, é necessário aceitar um espaço da morada feliz.

Nota-se com isso então um importante elo que conecta a presente proposta de reflexão pedagógica - no sentido durandiano: como uma força do ambiente psicossocial - aos estudos do primeiro espaço de acolhimento: à casa. "Todo espaço realmente habitado traz a essência da noção de casa" (BACHELARD, 1993, p.25). É por esse caminho que o olhar para o espaço da casa se aproxima ao da educação. O filósofo ensina por meio de suas imagens provocantes que o animus constrói o exterior da casa e a ânima o interior.

Psiquicamente falando, a imagem do feminino - ou a imagem da "mãe", como nos traz a psicanálise - se refere aqui à "construção" da vida íntima do próprio ser, que ao nascer passa logo a habitar um mundo, uma casa. E é por meio dessa que o ser sentirá que é, de certa forma, merecedor de um lugar no mundo. Há uma pedagogia do pertencimento que a casa realiza por si só. Por isso Bachelard (1993, p.26) nos re-encanta dizendo que ela "protege o sonhador, [o] permite sonhar em paz".

A casa é um abrigo: contra o mundo, a favor do Ser. Um lar, um valor, uma construção, um sonho, uma rede de gestos, elementos e movimentos psíquicos condensados. Pela imaginação simbólica, cada parte da morada é pensada, sonhada e construída, tem uma história para contar, tem um motivo para existir. E é em meio a esse emaranhado de sentidos que se entende a casa natal. Cada canto, cada parte, cada móvel, por carregarem anos de pensamento e projetos, por guardarem décadas e décadas de sentidos velados, por terem como motivo de existência a perenidade da existência humana, carregam e comunicam sentidos da vida por suas imagens uma imensa bagagem de mensagens à alma humana. 
Essa pedagogia da casa seria então pensada enquanto uma Pedagogia do acolhimento, por meio de uma força ontológica despida de preconceitos e que apenas acolhe o ser que se mostra pelo imaginário. A casa então, que segundo Bachelard é o berço do mundo, pode ser entendida primariamente como o fator do nascer e ser acolhido numa barriga, o ventre materno. Depois, como casa natal, local onde crescemos e vamos nos humanizando pelas imagens primeiras. Acordando arquétipos para dizer ao ser que ele já tem um lugar do mundo. "À semelhança de Gaston Bachelard e Henry Corbin, Gilbert Durand torna a colocar o indivíduo imaginante no seu verdadeiro lugar, isto é, no coração e nos horizontes das práticas (e dos seus 'métodos') do imaginário" (DUBORGEL, 1992, p.302).

Para Durand, não há uma linearidade para explicar a história, pois as vicissitudes históricas levam a uma confusão entre a História da Humanidade e a história da vida e do corpo. “Ora, se o histórico é um fator místico e não positivo, são as ambiências psicossociais que definem o existencial" (DURAND, 2002, p.388). Podemos entender então que esse nascimento enquanto processo simbólico no qual saímos do sono e vamos desenvolvendo a imaginação de acordo com a explosão de sentidos que se chega na adolescência simbólica. Com o desenvolvimento da juventude se chega à Idade da Razão, na qual as classificações de nossa espécie partem da história do corpo, ou seja, um espelhamento antropomórfico da realidade natural.

Neste trajecto de felicidade desenvolvem-se muitos cosmos intermédios, por exemplo os que são descritos por L'espace poétique e, particularmente, um microcosmos privilegiado, o microcosmos humanizado pelo trabalho e pelo sonho humano: a casa, a habitação humana que recapitula 'da cave ao sótão' os símbolos do mundo na sua pedra, nas suas traves, na sua lareira, no seu poço, nas suas caves húmidas e sombrias, nos seus casebres aéreos e secos. Todas as imagens, todas as metáforas substancialistas dos poetas remetem, afinal, para esta habitação do mundo, de que a minha casa é o último símbolo. Portanto, o símbolo revela-nos um mundo e a simbólica fenomenológica, explicita este mundo que - nas antípodas do mundo da ciência - é, no entanto, eticamente primordial, referente de todas as descobertas científicas do mundo (DURAND, 2004, p.65).

É o que se caracteriza como o deslocamento da explicação da filogênese pela ontogênese: “o erro suplementar das explicações históricas é o de afirmar que a filogênese reproduz a ontogênese. [...] Há num tal pensamento um processo de redução do gênero humano à gênese 
de uma pessoa [...]" (DURAND, 2002, p.389). Nessa pedagogia, Gilbert Durand afirma que são mais as expressões psicossociais que formam uma cultura do que a história. Existem muitas outras forças que podem levar a uma sociedade a pender por um sentido e não mais uma linearidade contínua.

Quanto à pedagogia [...], que Bachelard encontra uma confirmação: uma pedagogia da razão aberta, uma recusa do bloqueio intelectual, uma recusa das características esquizofrênicas de nossa educação ocidental. Se citarmos aqui esses teóricos do movimento científico mais avançado, o da microfísica, é nossa conclusão marcar claramente aos olhos ingenuamente científicos que podiam nos ler, a 'seriedade' da poética bachelardiana³ (DURAND, 1964, p.56).

Essa compreensão pedagógica que não é necessariamente pelo verbo, linguagem, ciência, mas primeiramente por esses outros gestos que a casa contém nos faz entender que a casa, literalmente, em cada canto, é uma rede de gestos condensados que vai informar ao ser que ele tem um lugar. A casa para Bachelard, estudada através dos poetas, vai ser sistematizada em seus cantos, informando um tipo de centros que se multiplicam em outros centros.

Toda casa é centro de um mundo para o sonhador, para aquele que, como a criança, ao nascer vai achar que é o centro do mundo. Cada pequeno canto vai se formando como outro centro, por exemplo, a tendência centralizadora do tédio, da solidão, e mesmo dos próprios sonhos. Em cada canto, a criança vai vivenciando essas informações que vão sendo acordadas e significadas através dos arquétipos e de seu jogo com os sentidos socializados das imagens do cotidiano.

E toda essa teia de relações vai permitir que a criança, em seu enraizamento na casa, possa então sonhar, viver em paz. A partir dessa segurança que a casa oferece, para Bachelard o ser humano cria casas e forma moradas, ou, pelo menos, deveria ser assim para todos, ainda que saibamos que exista uma imensa crise habitacional em nosso planeta.

A casa vai carregar então toda informação da cultura, família e de como toda uma sociedade se liga às repetições de suas ancestralidades. Ainda que cada casa seja extemporânea,

\footnotetext{
3 "Quant à la pédagogie [...] que Bachelard en trouve une confirmation : une pédagogie de la raison ouverte, un refus du blocage intellectuel, un refus des caractères schizophréniques de notre éducation occidentale. Si nous citons ici ces théoriciens du mouvement scientifique le plus avancé, celui de la microphysique, c'est pour, dans notre conclusion, bien marquer aux yeux naïvement scientistes qui pourraient nous lire, le 'sérieux' de la poétique bachelardienne".
} 
ou seja, única em seu tempo, a proteção psíquica que a casa oferece é universal: o ser para sonhar.

A casa comunica logo cedo ao ser que existe uma humanidade, no tempo e fora dele (a ancestralidade). É pelo lar que se é acolhido no mundo, primeiro, há um repouso nesse berço simbólico; e só mais tarde que se é "atirado ao mundo" das responsabilidades. Há toda uma rede de gestos manifestos numa morada que informa ao ser que ele é de imediato um valor. A morada emite, então, logo cedo os seus conselhos: estão ali os valores da humanidade, da cultura, da família. Esses, que acolhem, não cobram. Tal berço, que procura continuar de alguma forma o ventre da mãe, comunica ao ser um bem-estar, informa que é uma proteção. Esse sentido de guarda comunica centenas de virtudes que se fixam no ser, acordando a função do habitar.

As imagens de uma casa acordam arquétipos, despertam toda uma germinação de valores oníricos. O Ser sente que precisa então de proteção para sonhar, para bem sonhar. Bachelard $(1993$, p.62) irá ainda dizer que "contra tudo e contra todos, a casa nos ajuda a dizer: serei um habitante do mundo, apesar do mundo". Por que não continuar, estender por mais alguns anos os valores oníricos de uma residência? Por que não pensar uma pedagogia ancorada nos primeiros gestos que asseguram ao ser a sua possibilidade de Ser? Em uma morada se sonha; e nos outros espaços que recebem crianças como está a noção de proteção? É uma concepção de trabalho pedagógico que nos leva a extensão dos valores oníricos do lar para dentro da escola e nos aproxima de outras pedagogias.

Ao passo que Bachelard aplicou efetivamente sua prática como professor no ensino secundário em Bar-sur-Aube (há relatos também de que entre 19291935 Bachelard idealizou uma escola pública na cidade, o que efetivamente ocorreu e veio a se chamar Gaston Bachelard) e depois no ensino universitário em Dijon e depois na Sorbornne em Paris. Steiner experienciou a direção de uma escola a partir de sua teoria antroposófica, o nome da escola, Waldorf, se deu pelo fato de que Emil Molt, um diretor de uma fábrica de cigarros chamada Waldorf/Astória na cidade de Stuttgart, ao se identificar e se comprometer com as causas trabalhistas, sugeriu ao Steiner para fazer palestras aos trabalhadores sobre sua metodologia de educação. Em princípios de 1919, os próprios trabalhadores tiveram interesse de que seus filhos pudessem receber uma educação mais adequada e tal iniciativa prevaleceu até hoje em dia, onde na última década a pedagogia Waldorf cresceu muito no Brasil (ROCHA; SANTOS; PINHO, 2019, p.55). 
Na Pedagogia Waldorf a alfabetização começa mais tarde, por volta dos oito anos que é onde a razão começa a acordar, a estreitar a imaginação porque é quando a gente começa a compreender o tempo e a morte. Isso vai formar e adornar o mundo para querer se eternizar e é justamente esse simbolismo que a casa comunica em sua estrutura que repete a vontade da ancestralidade em manter nossas condições de sobrevivência.

Que imagem de concentração de ser, essa casa que se 'aperta' contra seu habitante, que se torna a célula de um corpo com suas paredes próximas! 0 refúgio contraiu-se. $\mathrm{E}$, mais protetor, tornou-se exteriormente mais forte. De refúgio passou a reduto. A choupana transformou-se em fortaleza da coragem para o solitário que nela deve aprender a vencer o medo. Tal morada é educativa (BACHELARD, 1993, p.62).

A continuidade da vida de uma família no mundo representa toda uma humanidade que se construiu por entre paredes (esse sim é o sentido dessa herança - pertença, acolhimento, lugar de descobertas, de troca, interações). Nas construções simbolizadas pelo conhecimento que se ergue, as paredes podem ser entendidas como uma forma de transmitir aos próximos a vontade de manter a humanidade da família viva e delimitada.

Assim, podemos partir para outro centro pedagógico da casa que é a cozinha, nisso seria muito interessante cogitar-se transformar o centro de uma escola na cozinha também. Sabemos que em nossa realidade brasileira a maioria das crianças vão para a escola por causa da merenda. Grande parte dos projetos sociais frisam essa importância, até no próprio isolamento imposto pela pandemia percebeu-se que algumas escolas pararam de dar aulas, mas continuaram a fornecer cestas básicas para as famílias dos alunos regularmente matriculados. Assim, a fome de saber é precedida pela fome material, isso move o comparecimento à escola. Nesse sentido também a Pedagogia do acolhimento se volta para o princípio da ânima na cozinha. E é na mesa da cozinha que podemos também enxergar uma horizontalidade, em que todos se sentam em volta da mesa, se reúnem para conversar e comer. É daí que a socialização relembra que até para aprender a falar, desde que nascemos, é pela necessidade da comida (a pedagogia da horizontalidade está relacionada com uma relação de não autoritarismo - aqui podemos dizer que os olhares estão despidos de autoritarismo, ainda que a autoridade do adulto guie este estar em partilha num aprendizado mútuo, na mesa redonda todos são igualmente beneficiados, 
alimentados e acolhidos).

É aí que Bachelard nos faz pensar justamente nessas provocações sobre o alinhamento do arquétipo da casa com os elementos. Desde a primitividade é pelo fogo que o homem aprendeu a cantar, o fogo da cozinha é um chamado no qual a gente se reúne para cantar, dançar e se unir nos ritmos do cotidiano.

É uma provocação em pensamento que traz para educação formal não mais o centro também, mas aquilo que está acontecendo nessa margem. Que brota entre a vontade e o sonho, presente na pré-escola naquilo que acontece no recreio, numa pedagogia do lazer. É naquelas aulas de artes que a criançada faz aquela bagunça com a tinta. E é nesse caos que o sentido existe para toda uma pluralidade da escola que acaba ficando à uma margem, na qual a Pedagogia do acolhimento pode estar concentrando mais atenção.

Assim, manter essa Pedagogia do acolhimento por mais tempo, é conceber que a criança enquanto sonha terá mais base para até ter condições futuras da criatividade necessária para a abertura para a ciência. O Professor Dr. Alberto Felipe Araújo $(2019$, p.38) afirma que: "pedagogos e educadores carecem de uma pedagogia da imaginação, de sabor bachelardiano, que os ajude a exercitarem-se na arte 'poética do devaneio' e que, a nosso ver, pode conciliarse com a pedagogia do imaginário tal como considera Bruno Duborgel", o mesmo ainda é dito também na compreensão de que na medida que por trás de todo homem há uma grande mulher, ademais, podemos dizer quando estudamos o imaginário, entendemos a questão sociológica de que existe por trás de todo o animus deve haver uma grande ânima, consequentemente, atrás de todo conceito há uma grande imagem. Então, podemos ainda passar as nossas deduções de que por trás de todo trabalho há um grande sonho, e a casa, enquanto centro de sonhos, é justamente essa força de possibilidade de manter o Ser enquanto Verbo que entende que o estudo é tudo na Vida. Contudo, há que se tomar cuidado no entendimento da noção de Vida a partir do conceito de ressonância e reverberação presentes em A poética do espaço e de como eles podem ser entendidos na pedagogia.

A um primeiro nível, o poema entrega-se-nos através das 'ressonâncias': nós 'ouvimos' o poema, as suas ressonâncias 'dispensam-se nos diversos planos da nossa vida no mundo'. A um segundo nível, ele provoca em nós a sua instância realmente poética, já não evocando apenas o nosso eu empírico, a nossa biografia, a nossa contingência, mas interpelando o ser: momento da 
repercussão que 'nos chama a um aprofundamento da nossa própria existência' e nos 'recolhe', na dupla acepção do termo. Inversamente, o comentarismo psicologizante, tão ocupado em 'descrever' sentimentos, eterniza-se e afundase nas ressonâncias. [...] À pedagogia subentendida pelos processos da paráfrase e da informação, ou da tradução e da inspecção-desconfiança das imagens, contrapõe-se portanto a pedagogia da comunicação poética e da deriva imaginativa, da repercussão, da admiração e da entrega às imagens como a nós próprios quando nos reencontramos (DUBORGEL, 1992, p.315).

Trabalhando então a fenomenologia na $A$ poética do Espaço, Bachelard pretende empreender verdadeiramente um aprofundamento na imaginação espacial, retornamos a uma síntese de seus capítulos, nos quais, no primeiro capítulo do livro, se desvelou o sentido da cabana, como justamente um ponto de partida da superação dos aspectos psicanalíticos da casa em relação ao ser humano. Por exemplo, a própria antropomorfia da casa, em que se subentende que o sótão representa o inconsciente, ao passo que o porão é o lugar das pulsões sexuais.

Entender a imagem pela imagem é o grande desafio fenomenológico bachelardiano de perceber, nesse dado contexto de uma educação de espaços não formais, não por uma tradução de sentidos, mas pelos sentimentos do ânima por trás do animus. Esse ser humano que cresce em sua casa, como uma delimitação necessária ao seu crescimento, assim como também como proteção para seus traumas, como no capítulo da "Gaveta, cofres e armários", esses segredos que são guardados. O ser humano cria suas proteções instintivas contra esse mundo, essa contra natureza, como nos capítulos "O ninho", "A concha".

O aspecto pedagógico da Poética do Espaço também pode abarcar a transgressão, que Bachelard também tem em mente na educação pelos momentos de desobediência, quando a criança é levada pela reflexão nos cantos em que se isola, como no processo educativo do castigo, em que a criança devia ficar no cantinho da reflexão.

Todos esses processos estão ligados a miniaturização do conhecimento da vida, ou seja, em transformar os saberes educativos mais palpáveis e mesmo valiosos, pois a condensação é um valor de consolidação: "possuo tanto melhor o mundo quanto mais hábil for em miniaturizáIo" (BACHELARD, 1993, p.159). A própria relação da criança em admirar o macro, os grandes brinquedos e na medida que ela vai se tornando adulto, vai condensando o valor de miniaturas, bijuterias, joias, enfim, o valor das coisas pequenas vai superando as grandes.

Por fim, quando nos aproximamos da noção de "Imensidão íntima", pensamos que é o 
momento da criança se tornar um adulto e conhecer a exterioridade simbolizada pelas florestas. E assim repensar seus processos interagindo dialeticamente com as infinitas relações entre exterior e interior.

Por fim, para finalizar o capítulo sobre a "Fenomenologia do Redondo", entendemos mais um desafio de leitura interpretativa dessa obra de Bachelard, quando ele se volta para as raízes da esfericidade parmenidiana, ou se inspira em Jaspers e Van Gogh ao dizer que "a vida é redonda" (VAN GOGH apud BACHELARD, 1993, p.236), ele passa a caracterizar uma fenomenologia metapsicológica da relação entre o ser, a comunidade e a aparência. As esferas, como bem sabemos, em nossa sociedade atual, de bolhas de relações, são um convite a congregações de pensamento. O que é necessário lembrar é que vivemos numa grande esfera/casa chamada mundo que contém a intersecção de todas outras esferas. A escola também é uma esfera que dá seus frutos pelo amadurecimento do ser, desde que se tenha esse sentido de coletividade instintiva que transcenda a individualidade no processo de sair de si para crescer com o outro, isto é: o acolhimento no qual os processos de desvelar e velar,

\footnotetext{
Ajudaram-nos a nos 'desfilosofarmos', a afastarmos todas as seduções da cultura, a colocarmo-nos à margem das convicções adquiridas num longo exame filosófico do pensamento cientifico. A filosofia amadurece-nos com muita rapidez e nos cristaliza num estado de maturidade. [...] Quando se pode dizer como se imagina, já não se imagina. Seria preciso, então, desamadurecer (BACHELARD, 1993, p.239).
}

A complexidade dialética, entre interior e exterior, amadurecer e desamadurecer se altera descontinuamente por novas perspectivas e desafios da educação. A pedagogia da poética do espaço não é uma pedagogia da espacialidade vazia, do vácuo, mas, muito pelo contrário, uma educação plena, do cheio, criativo, preenchendo sempre novas possibilidades de sentidos.

\section{Considerações finais}

“Uma das máximas da educação prática que regeneram a minha infância: 'não coma com a boca aberta'"' (COLETTE apud BACHELARD, 1993, p.215).

Por meio do pluralismo epistemológico filosófico da pedagogia do acolhimento 
esperamos compreender a significação de que cada casa reverbera um ser da humanidade e se multiplicarmos casa por casa, na ideia da sociedade, chegamos a uma cidade científica. Nesse conceito bachelardiano, essa cidade científica significa justamente um pluralismo coerente entre diferentes pedagogias científicas, a coerência advém do conhecimento mútuo, do respeito, e da negação respeitada pelo ato epistemológico de selecionar aquilo que já não é atual, negar, e abarcar aquilo que continua vigente num novo conhecimento. Lembrando que a pedagogia científica de Bachelard está toda baseada na valorização do erro, os erros nos movem, já que não existem verdades primeiras, mas sim erros primeiros. Além disso, vale ressaltar que nessa cidade científica, não é a escola que deve ser feita para a sociedade, mas sim o inverso, a sociedade é feita para uma escola entendida como cidade científica, então a escola é justamente esse espaço de experimentações metodológicas, de aplicação de teorias, e de inovação e superação das dificuldades da própria sociedade.

A presente investigação procurou demonstrar então um considerável potencial reflexivo da educação em A poética do Espaço. As diversas imagens que Bachelard traz a partir de um estudo (fenomenológico) sistematizado da imaginação, abriram imensas possibilidades para a criatividade pedagógica, principalmente para aqueles que procuram re-pensar o espaço educacional. Sem trazer respostas, mas procurando formular claramente os problemas que provocam um estudante a sonhar e ter nisso uma pedagogia da acolhida, do repouso, por um espaço seguro que receba o ser para a sua jornada, para a sua existência onírica e alternadamente real, o presente estudo percorreu seu percurso de uma experiência do pensamento pela dignidade de se apresentar uma humilde exposição reflexiva do livre pensar bachelardiano.

\section{Referências}

ARAÚJO, A. F. Pedagogia e educação da imaginação sob olhar de Bachelard: para um novo espírito pedagógico. In: ROCHA, G. K. (org.). Bachelard, um livro vivo: homenagem aos 135 anos de nascimento do filósofo. Ed. Phillos: Goiânia, 2019, p.34-70.

BACHELARD, G. A poética do espaço. Trad. Antonio de P. Danesi. São Paulo: Martins Fontes, 1993. 
DUBORGEL, B. Imaginário e pedagogia. Instituto Piaget: Lisboa, 1992.

DURAND, G. Science objective et conscience symbolique dans l'œuvre de Gaston Bachelard. Cahiers Internationaux de Symbolisme, n. 4, Genève / Bruxelles, p.41-59, 1964.

DURAND, G. As estruturas antropológicas do imaginário: uma introdução à arquetipologia geral. São Paulo: Martins Fontes, 2002.

DURAND, G. $O$ imaginário: ensaio acerca das ciências e da filosofia da imagem. Trad. Renée Eve Levié. Rio de Janeiro: DIFEL, 2004.

ELIADE, M. Imagens e símbolos: ensaio sobre o simbolismo mágico-religioso. São Paulo: Martins Fontes, 1991.

ROCHA, G. K. SANTOS, D. M. PINHO, R. O. A infância em Bachelard e Steiner: um ponto de vista da educação antroposófica contra a crítica de Onfray. Interação, Varginha, v.21, p.51 -67, 2019.

STEIN, M. O mapa da alma: uma introdução à Jung. SP: Cultrix, 2000. 